\title{
Electron Densities \& Cyclo-Voltammetry Studies of Mg, Al and Ca Calix-Aren Complexes
}

\author{
Mahsa Aliakbarzadeh Roudsary ${ }^{1}$, Karim Zare ${ }^{1, *}$, Hossein Aghaei ${ }^{1}$, Majid Monajjemi ${ }^{2 *(D)}$ \\ Department of Chemistry, Science and Research Branch, Islamic Azad University, Tehran, Iran \\ 2 Department of Chemical engineering, Central Tehran Branch, Islamic Azad University, Tehran, Iran \\ * Correspondence: K_Zare@sbu.ac.ir; Maj.Monajjemi@iauctb.ac.ir;
}

Scopus Author ID 6701810683

Received: 18.06.2020; Revised: 4.07.2020; Accepted: 5.07.2020; Published: 7.07.2020

\begin{abstract}
Calixarenes are preferable for metal extraction because of the easy synthesis of a great number of derivatives, which allows comparing the impact of cavity size, conformation, functional groups, and other factors on the extraction behavior, and the flexibility to design a proper ligand to recognize a metal ion selectively. In this work, theoretically, it has been discussed on the specific Calix $[\mathrm{n}]$ and related cation in point of density and electrical potential via electron densities \& cyclevoltammetry studies.
\end{abstract}

Keywords: Electron densities; cyclo-voltammetry; Calix-aren.

(C) 2020 by the authors. This article is an open-access article distributed under the terms and conditions of the Creative Commons Attribution (CC BY) license (https://creativecommons.org/licenses/by/4.0/).

\section{Introduction}

In 1872 Adolf von Baeyer mixed various aldehydes, including $\mathrm{CH}_{3} \mathrm{CHO}, \mathrm{C}_{6} \mathrm{H}_{5} \mathrm{OH}$, and acid in media of $\mathrm{pH}=0$. The resulting represented the novel chapter of what was to become the subject of phenol/formaldehyde chemistry. Leo discovered that those materials could be transformed into a hard, brittle substance, which he marketed as "Bakelite", the initial commercial synthetic plastic. The success of him start into the chemistry of the phenol/formaldehyde phenomenon, consequently with this discovery, another Australian scientist (Alois Zinke) exhibited that formaldehyde in the presence of a strong base yield mixtures containing, inter alia, cyclic tetramers. At the same time, Joseph Niederl obtained similar cyclic behavior from the acid-catalyzed media of resorcinol and aldehydes. The Calixarens are a macrocycle oligomer, including a hydroxyl acylation from phenol structure and an aldehyde. The Calixarene name is derived from Calix due to their types of molecule resembles a vase and from the "aren" that refers to the aromatic building blocks. They have hydrophobic cavities that can hold smaller molecules and belong to the category of host-guest chemistry. Those are synthetic receptors via phenol moieties attached to the methylene groups[1]. Calixs can be substituted at the lower rim for producing a variety of ionospheres, that were shown to be suitable structure for complexation [2] transition metal[3,4] and lanthanide metal cations [5]. Among the functionalized Calixarene groups, the Calix-Quinones has strongly attracted interest. Some of those compounds were employed to study interesting redox systems and charge-transfer complexes, as well [6]. Most Calix-Quinones have been synthesized through chemical oxidation that comprises unsub-situated phenol rings [7]. It is noteworthy that, to date, no Calixarene with adjacent Quinone units has been reported. 
Recently, a straightforward synthesis of the 1, 3-diquinone-calix [4]-arene has been explained with a good yield through electrochemical oxidation of the dihydroxy-diamide precursor [8]. From several of macrocyclic compounds, Calixarenes[1-6] are suitable for metal extraction due to easy synthesis of a wide variety of their derivatives, which allows comparing the impact of cavities sizes, conformation, functional groups, and other factors, and the flexibility to design a proper ligand to selectively recognize a metal ion $[5,8]$. The expensive calculation of computational resources required for evaluating the energies and structures of calix[n]arenas have prevented large ab initio and density functional theories until recently Calixarenes [9] have received much attention recently as one of the most widely employed molecular frameworks for the construction of many versatile supramolecular systems. [10] Much research has been done examining hydrogen bonding by studying weakly bound complexes. Hydrogen bonding belongs to the important weak interactions in nature, being intimately involved in the structure and properties of water in its various phases in large molecules such as proteins, nucleic acids, and Calixarenes. Most hydrogen bonds are of $\mathrm{YH}$...H type, where $\mathrm{Y}$ is an electronegative atom having one or more lone electron pairs or a raging of excess electron density like the atomic $\pi$-system. About the hydrogen bonding properties of Calixarenes, we would like to pay our attention to the hydrogen bonding properties of Calix [8] arene by density functional theory methods.

Calixarenes belong to the ionophores, lipid-soluble molecules which are able to transport ions across the lipid bilayer of the cell membrane. Ionophores have been frequently used for explanation or simulation of real transporting processes of metals, their ions, and other species across the cell membranes (phospholipid monolayers and bilayers)[11,12]. Therefore, it is necessary to elucidate the factors influencing these transporting processes, e.g., the presence of low molecular weight organic acids, $\mathrm{pH}$. It is obvious which the electrochemical approaches have proved several times to be very suitable for the study of various environmental matters as well as in the characterization and description of those mechanisms, mainly voltammetry and electrochemical impedance spectroscopy (EIS) [13].

Two different deposition reactions are compared, self-assembly, and an electrochemically induced deposition at several applied potentials. The optimum adsorption situations for individual deposition activities of both the species are determined from the reduction of desorption peaks, and the properties of the modifying layers are studied by electrochemical measurements in simple redox systems. Calixarenes are efficient sodium ionophores and are applied as chemical sensors. With the right chemistry, these molecules exhibit great selectivity towards other cations. Calixarenes are used in commercial applications as sodium selective electrodes for the measurement of sodium levels in the blood. Calixarenes also form complexes with cadmium, lead, lanthanides, and actinides. Calix [5] arene and the $\mathrm{C}_{70}$ fullerene in $p$-xylene from a ball-and-socket supramolecular complex (Figure 1) [13, 14]

Molecular self-assemblies of pyrogallolarenes led to the huge supramolecular assemblies. Both in the crystalline state and solution media, they are known for forming hexamers, which are akin to certain Archimedean solids with an internal volume of around one cubic nanosciences. Isobutylpyrogallol [4] arene are held together by 50 intermolecular hydrogen bonds. The remaining hydrogen bonds are intramolecular. The cavities are filled through several solvent systems [15, 16]. Calixarenes usually and more specifically, Calix [4] arene have been extensively applied as molecular platforms for building up supramolecular catalysts. The designing of those types of catalysts are in functionalizing the upper rim of the 
lower rim of Calixarenes with ligands able for binding metal cations, notably $\mathrm{Cu}$ (II) or $\mathrm{Zn}$ (II), or other active functions (Table 1).
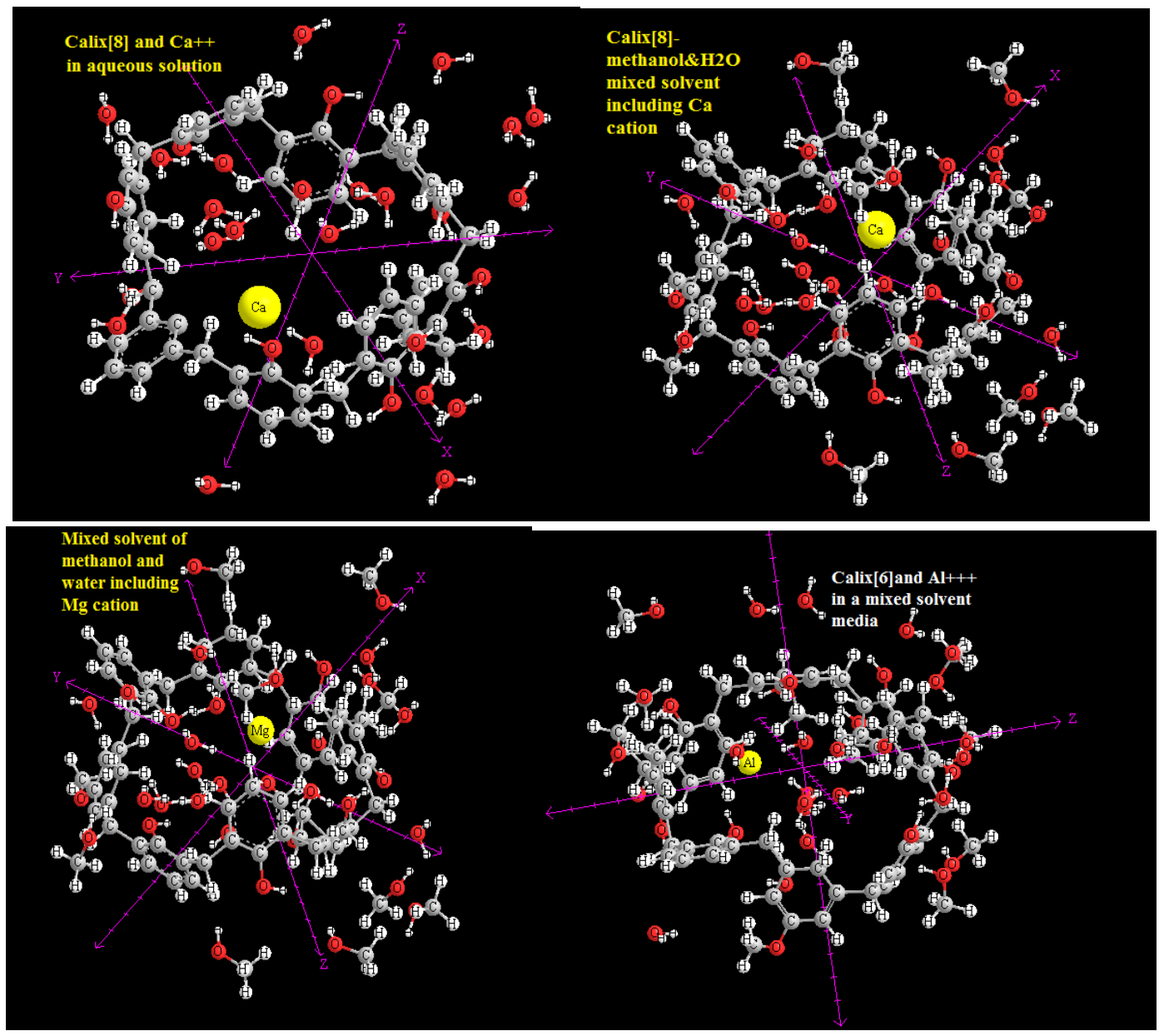

Figure 1. Optimized Calix [8] in various media and various cation complexes.

Self-assembly mechanisms on some surfaces of platinum, silver, iron, and mercury, have been explained in detail. However, the modification of gold electrodes via alkene thiols has probably been studied extremely [17]. The basic of self-assembling is the spontaneous formation of a modifier molecule monolayer on the solid surfaces, the modifier molecules being amphiphilic in their characters. Specifically, in the cases of a thiol/gold surface adsorption, these fundamentals may be formally considered as an oxidative addition of the S$\mathrm{H}$ bond to the gold surface, followed via reductive elimination of the hydrogen [18].

The self-assemblies depositions are generally explained as a three-step mechanism. The first one is the adsorption of the thiol on the gold surfaces towards the formation of an Au-S bond. The second one contains straightening of the alkyls chains, and the third step, which is the slowest, has been attributed to a reorientation of the terminal groups [19]. The SAM stabilities and the velocities of the mono-layers formation can be influenced through several factors, such as temperature, length of the alkyl or the solvent used [20]. Paik et al. described the influence of dissolved $\mathrm{O}_{2}$ gases or a redox couple on the self-assembly reaction described the effect by assuming that the electrons generated by adsorption reaction, that retard the further reaction of thiols with the electrode surfaces, are consumed by dissolved oxygen or by the redox couple (Figure 2) [21]. 
Table 1. Homo and Lumo calculation.

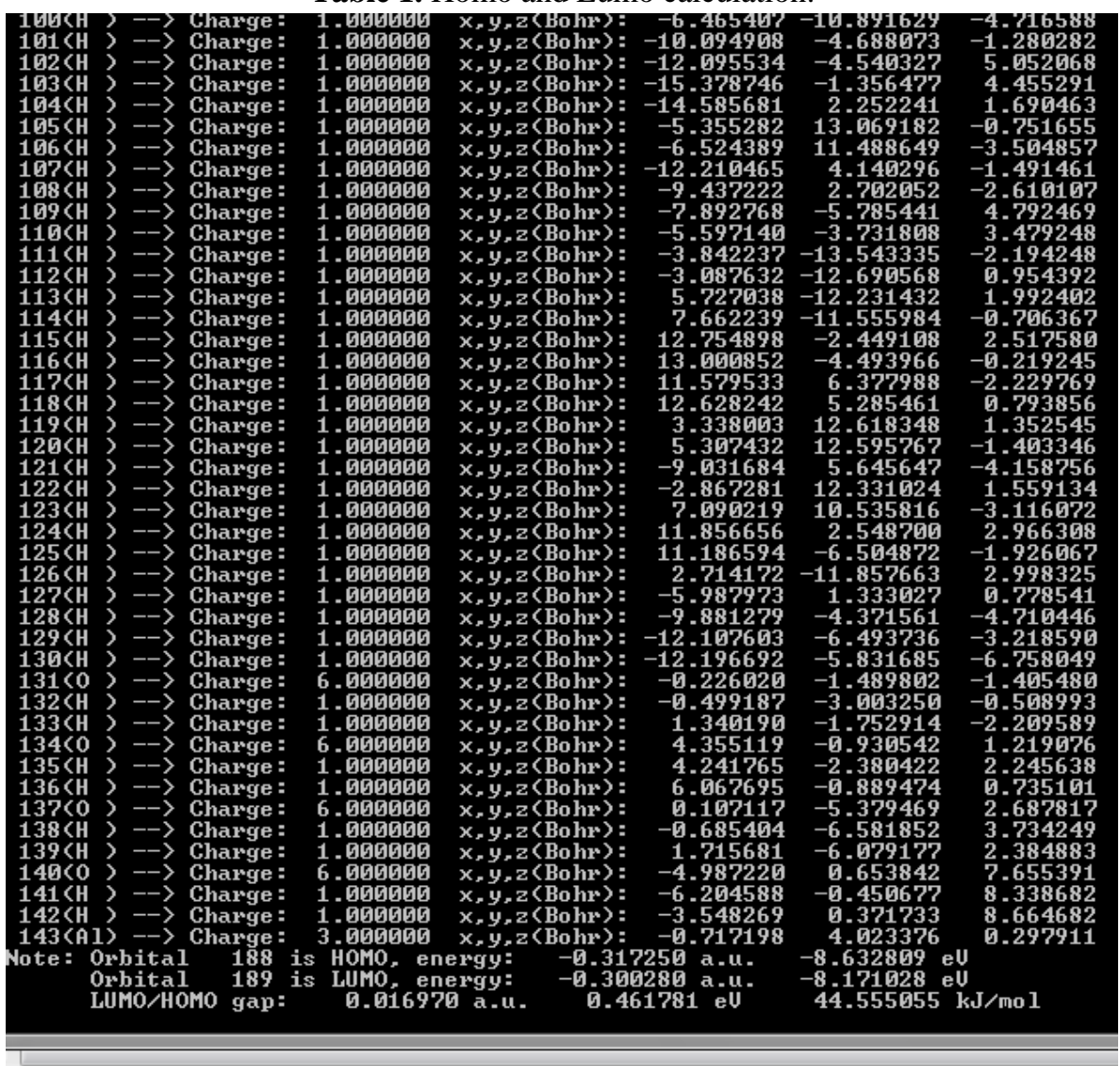

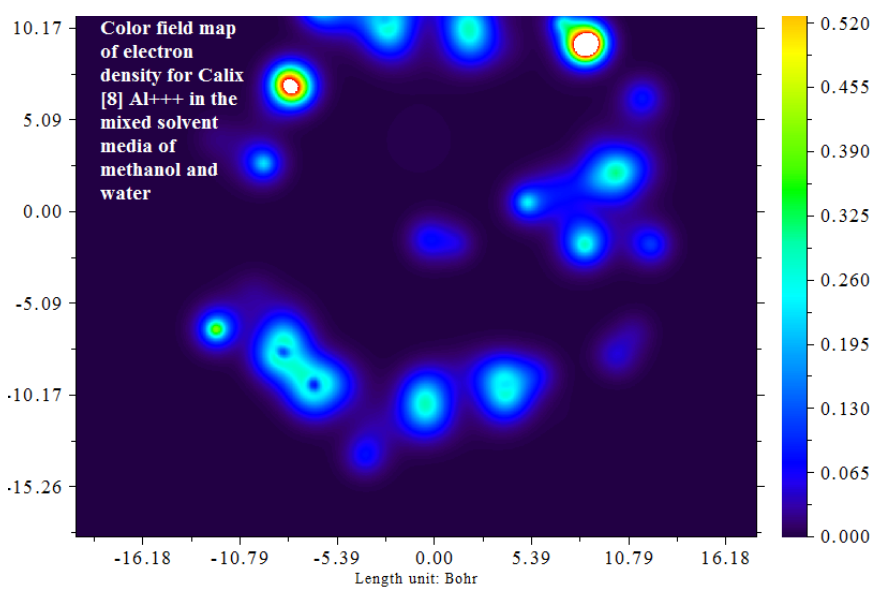

Figure 2. Color field map of electron density for Calix [8]- $\mathrm{Al}^{3+}$ in the mixed solvent of methanol and water media.

Self-assembling of monolayer is ordered molecular assemblies formed usually via the adsorption of the active surfactants on the solid surfaces. Especially, the self-assemblies of organosulfur adsorbate on the Au have attracted great attention in the recent decade(s).

The high specificity of the S-Au interaction allows for the introduction of several functional groups into such monolayers without interfering with the adsorption mechanism. The numbers of surface-active organosulfur compound that form monolayers have been increased recently. Those include dialkyl sulfides [20, 21] and disulfides, mercaptans, thiophenols, and several mercapto-substituted compounds. Calixarenes potentially can accelerate reactions taking place inside the concavities through the combination of local concentrations effect and polar stabilizations of the transition state. Extended resorcinol [4] arene cavities and are founded to 
accelerate the reaction rates of a Menshutkin reaction between quinuclidine and butyl-bromide. In hetero-Calixarenes the phenolic section is replaced through heterocycles, for example, via furans in calix[n]-furans and by pyridines in calix[n]-pyridines. Calixarenes have been used as the macrocycle portion of a Rotaxan, and two Calixarenes molecules covalently joined together by the lower rims form Carcerands. Calixarenes also form exo-Calix ammonium salts with aliphatic amines such as piperidine. In so far as hydrogen bonding is concerned, dimeric capsules from Calix [4] arene (substituted at their wide rim by four (aryl) urea groups) have been extensively studied 16 in solution 17 and characterized by several single-crystal X-ray structures (Figure 3) [22].

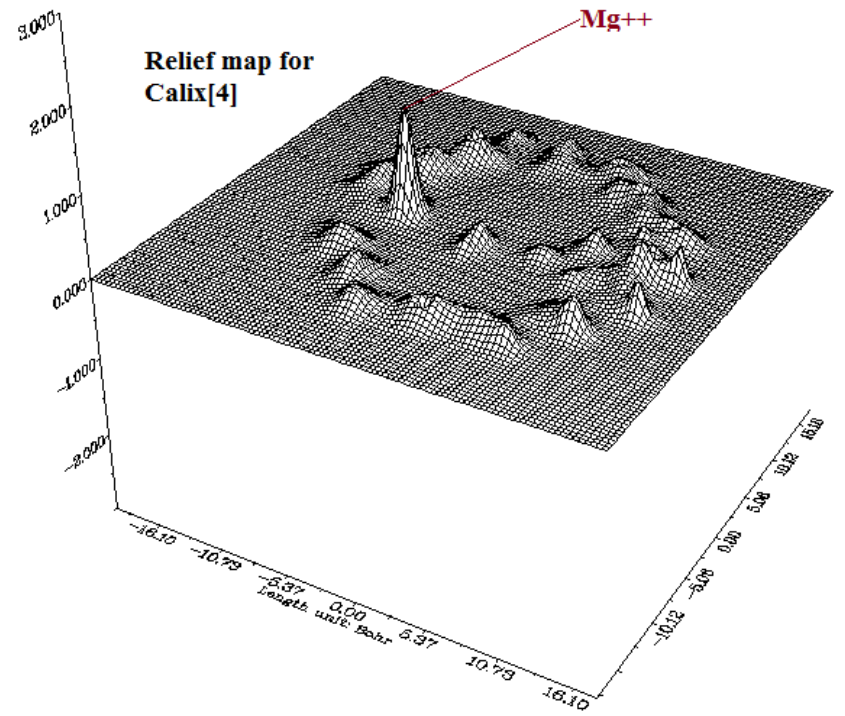

Figure 3. Relief map for Calix [4] in water media with dielectric=78.8.

If such a tetraurea is decorated with suitable sulfur functions, the formation of SAMs on gold should be possible. In addition, the attachment to the gold surface may lead to the permanent inclusion of a guest molecule, similar to carcerands. Dialkyl sulfide groups were attached to Calix [4] arene, to resorcarenes, and resorcarene - derived cavitands in order to obtain the respective SAMs on gold.

Based on some simulated works, in the wide range methods and basis sets in the field of Physical chemistry, Nanobiotechnology, quantum phenomenon, Nano capacitors, chemical biology, adsorption, and NMR shielding, we have run our works for yielding the best results in these areas.

\section{Materials and Methods}

Part of the systems, including Calix (8) $\mathrm{COOH}, 1$, 3-diquinone-calix [4]-arene, and some other functionalized Calixarenes, have been modeled with OM/MM methods based on our previous works[23-78] and the calculations are accomplished out with the Abinitio and MM methods. In this investigation, differences in force field are illustrated by comparing the calculated energy with CHARMM, AMBER, and OPLS force fields. Furthermore, HyperChem professional release 7.01 programs are used for additional calculations. For non-covalent interactions between metal particles and Calix (8) $\mathrm{COOH}$, the B3LYP method is unable to describe van der Waals by medium-range interactions. Therefore, the ONIOM methods, including 3 levels of 1-high calculation $(\mathrm{H}), 2$-medium calculation $(\mathrm{M})$, and 3-low calculation 
(L) have been performed in our study for calculating the non-bonded interactions between nanoparticles and Calix (8)COOH. The ab-initio and DFT methods are used for the model system of the ONIOM layers, and the semi-empirical methods of pm6 (including pseudo=lanl2) and Pm3MM are used for the medium and low layers, respectively. B3LYP and the most other popular and widely used functional are insufficient to illustrate the exchange and correlation energy for distant non-bonded medium-range systems correctly. Moreover, some recent studies have shown that inaccuracy for the medium-range exchange energies leads to large systematic errors in the prediction of molecular properties. Geometry optimizations and electronic structure calculations have been carried out using the m06 (DFT) functional. This approach is based on an iterative solution of the Kohn-Sham equation of the density functional theory in a plane-wave set with the projector-augmented wave pseudo-potentials. The Perdew-BurkeErnzerhof (PBE) exchange-correlation (XC) functional of the generalized gradient approximation (GGA) is also used. The optimizations of the lattice constants and the atomic coordinates are made by the minimization of the total energy (Figure 4).

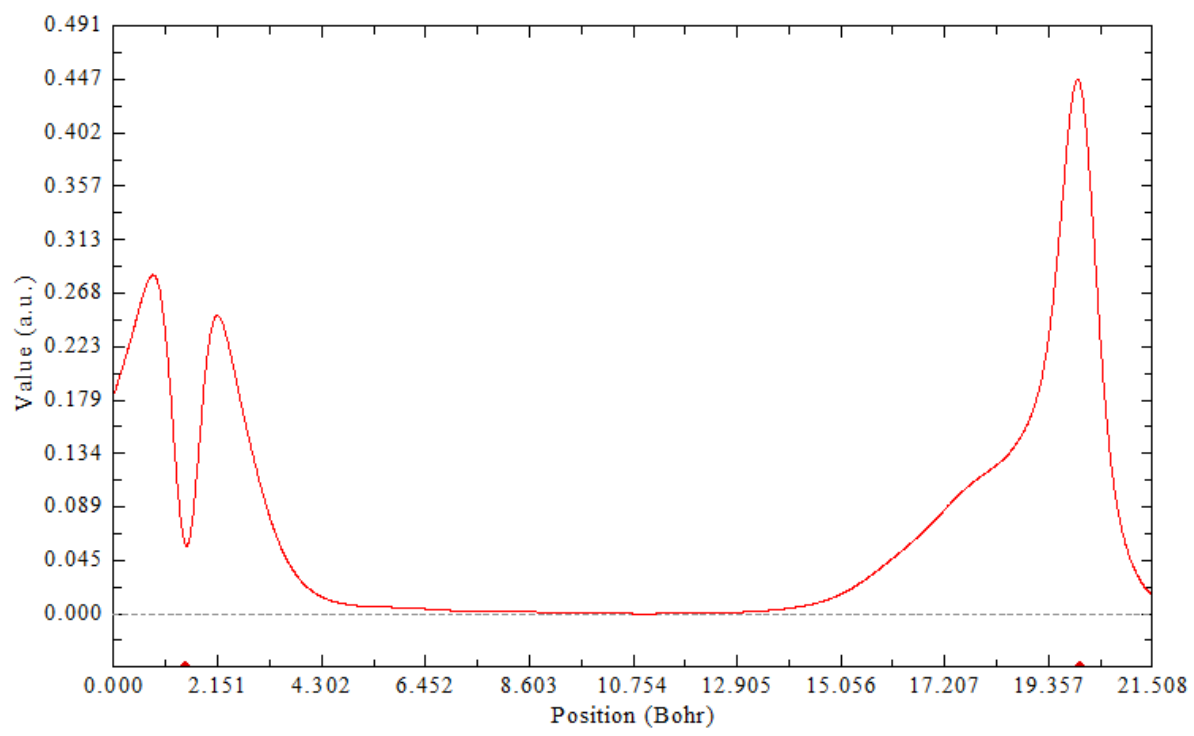

Figure 4. Electron density of Calix [6]-Ca in aqueous media.

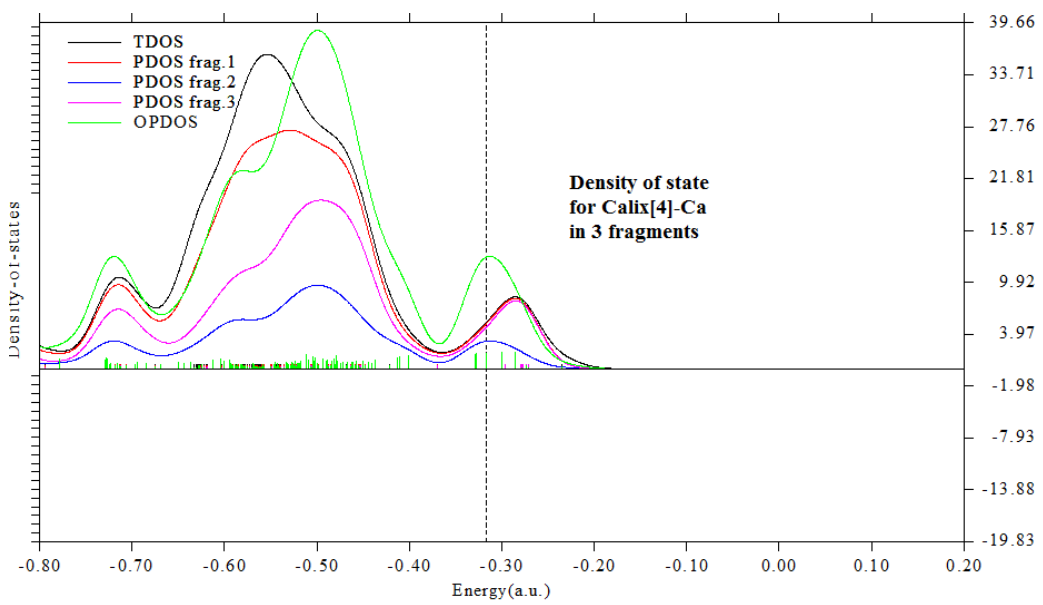

Figure 5. Density of state for Calix [4]-Ca ${ }^{2+}$.

The charge transfer and electrostatic potential-derived charge were also calculated using the Merz-Kollman-Singh chelp or chelpG the charge calculation methods based on molecular electrostatic potential (MESP) fitting are not well-suited for treating larger systems 
whereas some of the innermost atoms are located far away from the points at which the MESP is computed. In such a condition, variations of the innermost atomic charges will not head towards a significant change of the MESP outside of the molecule, meaning that the accurate values for the innermost atomic charges are not well-determined by MESP outside the molecule. The representative atomic charges for molecules should be computed as average values over several molecular conformations (Figure 5).

A detailed overview of the effects of the basis set and the Hamiltonian on the charge distribution can be found in references. The charge density profiles in this study have been extracted from first-principles calculation through an averaging process, as described in the reference. The interaction energy for the system was calculated in all items according to the equation as follows: $\Delta E_{S}(e V)=\left\{E_{\text {Complex }}-\left(\sum_{i=1}^{n}(\right.\right.$ metal - Calix $\left.[n])\right\}$ (1) Where the " $\Delta E_{S}$ " is the stability of energy. The electron density, electron spin density, electron localization function (ELF), total electrostatic potential (ESP), value of orbital wave-function, the electrostatic potential from nuclear atomic charges and localized orbital locator (LOL) which has been defined by Becke \& Tsirelson, as well as the exchange-correlation density, correlation hole, and correlation factor, and the average local ionization energy using the Multifunctional Wave-function analyzer have also been calculated in this study. The contour line map was also drawn using the Multiwfn software [79]. The solid lines indicate positive regions, while the dash lines indicate negative regions. The contour line corresponding to VdW surface, which is defined by R. F. W. Bader, is plotted in this study. This is specifically useful to analyze the distribution of electrostatic potential on VdW surface.

\subsection{Theoretical background.}

2.1.1. Electron density.

The electron density has been defined as $\rho(r)=\eta_{i}\left|\varphi_{i}(r)\right|^{2}=$ $\sum_{i} \eta_{i}\left|\sum_{l} C_{l, i} \chi_{i}(r)\right|^{2}(\mathbf{1})$. Where $\chi$ is basis function, $\eta_{i}$ is the occupation number of orbital $(i), \varphi$ is the orbital wave function, and $C$ is a coefficient matrix. Atomic unit for electron density can be explicitly written as: $\nabla \rho(r)=\left[\left(\frac{\partial \rho(r)}{\partial(x)}\right)^{2}+\left(\frac{\partial \rho(r)}{\partial(y)}\right)^{2}+\left(\frac{\partial \rho(r)}{\partial(z)}\right)^{2}\right]^{\frac{1}{2}}(2) \nabla^{2} \rho(r)=\frac{\partial^{2} \rho(r)}{\partial x^{2}}+\frac{\partial^{2} \rho(r)}{\partial y^{2}}+$ $\frac{\partial^{2} \rho(r)}{\partial z^{2}}(\mathbf{3})$.

Locally depleted and locally concentrated are the positive and negative values of these functions, respectively. The relationships between $\nabla^{2} \rho$ and valence shell electron pair repulsion or VSEPR model, electron localization, chemical bond type, and chemical reactivity have been investigated by Bader. The kinetic energy density is not uniquely defined, since the expected value of kinetic energy operator $\left\langle\varphi\left|-\left(\frac{1}{2}\right) \nabla^{2}\right| \varphi>\right.$ (4) can be recovered by integrating kinetic energy density from alternative definitions. One of the commonly used definition is: $k(r)=-\frac{1}{2} \sum_{i} \eta_{i} \varphi_{i}^{*}(r) \nabla^{2} \varphi_{i}(r)(5)$. Lagrangian kinetic energy density, "G(r)" is also known as positive definite kinetic energy density.

$G(r)=\frac{1}{2} \sum_{i} \eta_{i} \mid \nabla\left(\left.\varphi_{i}\right|^{2}=\frac{1}{2} \sum_{i} \eta_{i}\left\{\left[\left(\frac{\partial \varphi_{i}(r)}{\partial(x)}\right)^{2}+\left(\frac{\partial \varphi_{i}(r)}{\partial(y)}\right)^{2}+\left(\frac{\partial \varphi_{i}(r)}{\partial(z)}\right)^{2}\right]\right\} \quad\right.$ (6). $K(\mathbf{r})$ and $G(\mathbf{r})$ are directly related by Laplacian of electron density $\frac{1}{4} \nabla^{2} \rho(r)=G(r)-K(r)$ (7). Savin et al. have investigated the ELF in the viewpoint of kinetic energy, which makes ELF also meaningful for Kohn-Sham DFT wave-function or even post-HF wave-function. They indicated that $D(\mathbf{r})$ 
reveals the excess kinetic energy density caused by Pauli repulsion, while $D 0(\mathbf{r})$ can be considered as Thomas-Fermi kinetic energy density[79].

\section{Results and Discussion}

This study mainly focuses on voltammetry recognition of some Cation by various Calix[n]arene such as Calix [4] arene Diquinone Diacidtheand Calix (8) $\mathrm{COOH}$ in a nonbonded system the physical and chemical properties are shown in figures (1-5). As it is indicated in (tables 1-5), the electrical properties can be obtained from changes between Calix and cation interactions. Eta index and ECP Electron densities, energy densities, Potential energy densities, ELF, LOL, and Ellipticity of the various electron densities, for cation complex @ Calix arene were calculated of each simulation (Tables 1-7). The voltammetry study on a water-soluble Calix [n] arene and Calix [4] arene -diquinone - diacid (CDA) in the specific pH ranges and at the presence of cation provided important information about the unique electrochemical behavior of CDA-cation complex. Using $\mathrm{CDA}, \mathrm{Mg} 2+, \mathrm{K}+$, and $\mathrm{Ca} 2+$ ion in aqueous solution can be recognized quantitatively by voltammetry techniques. The electrochemical behavior of CDA is very similar to that of simple Quinone derivatives such as $p$-benzoquinone in the same conditions. The irreversible redox wave of free CDA is due to the proton-coupled electrochemical reduction. The largest electron localization is located on the interaction between $\mathrm{Ca} 2+$ and Calix [4], while for the Calix [8], the $\mathrm{k}+$ has the largest ELF, so via this kind of study, it can be defined the specific Calix for each of the cations. The electron motion is more likely to be confined within that region. If electrons are completely localized in the Ca2+-Calix \{4], they can be distinguished from the ones outside. As shown in tables 18 the large ELF is close to the alkali atoms. The regions with large electron localization need to have large magnitudes of Fermi-hole integration, which would lead the nanoparticles towards superparamagnetic. The fermi hole is a six-dimension function, and as a result, it is difficult to be studied visually. Based on equations 12, 13, and 14, Becke and Edgecombe noted that the Fermi hole is a spherical average of the spin, which is in good agreement with our results.

ELF [79] indicates that it is actually a relative localization and must be accounted for within the range of $[0,1]$. A large ELF value corresponds to largely localized electrons, which indicate that a covalent bond, a lone pair, or inner shells of the atom is involved. According to equation 16, LOL can be interpreted similarly to ELF in terms of kinetic energy, though; LOL can also be interpreted in terms of localized orbitals. Small (large) LOL value usually appears in the boundary (inner) region of localized orbitals due to the large (small) gradient of orbital wave-function in this area. The value range of LOL is identical to ELF, namely [0, 1] [79].

The total electrostatic potential (ESP) measures the electrostatic interaction between a unit point charges placed at $\mathbf{r}$ and the system of interest. A positive (negative) value implies that the current position is dominated by nuclear (electronic) charges. Molecular electrostatic potential (ESP) has been widely used for the prediction of nucleophilic and electrophilic sites for a long time. This result implies that the protonation of reduced Quinone is considerably inhibited when $\mathrm{Ca}^{2+}$ is bound to CDA. Generally, it is well known that the process of electron transfer to Quinone is coupled with proton transfer reaction in aqueous solution. It is also valuable in studying hydrogen bonds, halogen bonds, molecular recognition, and the intermolecular interaction of aromatics [79]. 
Table 2. All Electron Densities of Al (1) - Calix [8] COOH, Ca (1)-Calix [8] COOH, Mg (1)-Calix [8] COOH $\mathrm{Al}$ (2)-1, 3-diquinone-calix [4]-arene, $\mathrm{Mg}$ (2)-1, 3-diquinone-calix [4]-arene and $\mathrm{Ca}$ (2)-1, 3-diquinone-calix [4]arene.

\begin{tabular}{l|c|c|c|c} 
Cation & $\begin{array}{c}\text { Density of all- } \\
\text { electron }\left(\mathbf{1 0}^{-\mathbf{3}}\right)\end{array}$ & $\begin{array}{c}\text { Density of alpha } \\
\left(\mathbf{1 0}^{-\mathbf{3}}\right)\end{array}$ & $\begin{array}{c}\text { Density of Beta } \\
\left(\mathbf{1 0}^{-\mathbf{3}}\right)\end{array}$ & Spin Density \\
\hline $\mathrm{Al}(1)$ & 0.18 & 0.09 & 0.09 & 0.0 \\
\hline $\mathrm{Al}(2)$ & 0.18 & 0.09 & 0.09 & 0.0 \\
\hline $\mathrm{Mg}(1)$ & 0.22 & 0.11 & 0.11 & 0.0 \\
\hline $\mathrm{Mg}(2)$ & 0.24 & 0.12 & 0.12 & 0.0 \\
\hline $\mathrm{Ca}(1)$ & 0.36 & 0.18 & 0.18 & 0.0 \\
\hline $\mathrm{Ca}(2)$ & 0.34 & 0.17 & 0.17 & 0.0
\end{tabular}

Table 3. Some physical properties of $\mathrm{Al}$ (1) - Calix [8] COOH, Ca (1)-Calix [8] COOH, Mg (1)-Calix [8] $\mathrm{COOH} \mathrm{Al}$ (2)-1, 3-diquinone-calix [4]-arene, $\mathrm{Mg}$ (2)-1, 3-diquinone-calix [4]-arene and $\mathrm{Ca}$ (2)-1, 3-diquinonecalix [4]-arene.

\begin{tabular}{l|c|c|c} 
Cation & $\begin{array}{c}\text { Laplacian of electron } \\
\text { density }\left(\mathbf{1 0}^{-\mathbf{1}}\right)\end{array}$ & $\begin{array}{c}\text { Electron localization } \\
\text { function }(\mathbf{E L F})\left(\mathbf{1 0}^{-\mathbf{3}}\right)\end{array}$ & $\begin{array}{c}\text { Local information entropy } \\
\left(\mathbf{1 0}^{-\mathbf{4}}\right)\end{array}$ \\
\hline $\mathrm{Al}(1)$ & -0.28 & 0.48 & 0.32 \\
\hline $\mathrm{Al}(2)$ & -0.34 & 0.33 & 0.31 \\
\hline $\mathrm{Mg}(1)$ & -0.36 & 0.25 & 0.35 \\
\hline $\mathrm{Mg}(2)$ & -0.32 & 0.31 & 0.30 \\
\hline $\mathrm{Ca}(1)$ & -0.36 & 0.44 & 0.32 \\
\hline $\mathrm{Ca}(2)$ & -0.32 & 0.21 & 0.40
\end{tabular}

Table 4. Average local ionization energy, RDG and ESP of Al (1) - Calix [8] COOH, Ca (1)-Calix [8] COOH, $\mathrm{Mg}$ (1)-Calix [8] COOH Al (2)-1, 3-diquinone-calix [4]-arene, $\mathrm{Mg}$ (2)-1, 3-diquinone-calix [4]-arene and Ca (2)-1, 3-diquinone-calix [4]-

\begin{tabular}{|c|c|c|c|c|}
\hline Cation & $\begin{array}{l}\text { Reduced density gradient(RDG) } \\
\qquad\left(\mathbf{1 0}^{+1}\right)\end{array}$ & $\begin{array}{c}\text { Average local } \\
\text { ionization energy }\end{array}$ & $\begin{array}{l}\text { ESP from electron } \\
\text { charge }\left(1^{2}\right)\end{array}$ & $\begin{array}{l}\text { Lagrangian kinetic } \\
{[G(r)] \text { energy }\left(10^{-3}\right)}\end{array}$ \\
\hline $\mathrm{Al}(1)$ & 0.38 & 0.31 & -0.21 & 0.42 \\
\hline $\mathrm{Al}(2)$ & 0.30 & 0.33 & -0.51 & 0.41 \\
\hline $\operatorname{Mg}(1)$ & 0.45 & 0.44 & -0.14 & 0.24 \\
\hline $\operatorname{Mg}(2)$ & 0.15 & 0.41 & -0.24 & 0.33 \\
\hline $\mathrm{Ca}(1)$ & 0.26 & 0.25 & -0.26 & 0.12 \\
\hline $\mathrm{Ca}(2)$ & 0.22 & 0.12 & -0.28 & 0.11 \\
\hline
\end{tabular}

Table 5. of Al (1) - Calix [8] COOH, Ca (1)-Calix [8] COOH, Mg (1)-Calix [8] COOH $\mathrm{Al}$ (2)-1, 3-diquinone-calix [4]-arene, $\mathrm{Mg}$ (2)-1, 3-diquinone-calix [4]-arene and $\mathrm{Ca}$ (2)-1, 3-diquinone-calix [4]-

\begin{tabular}{l|c|c|c|c|c|c} 
Atom(number) & $\begin{array}{c}\text { Density of all- } \\
\text { electron(10 }\end{array}$ & $\begin{array}{c}\text { Density of } \\
\text { alpha } \\
\left(\mathbf{1 0}^{-3}\right)\end{array}$ & $\begin{array}{c}\text { Density of } \\
\text { Beta } \\
\left(\mathbf{1 0}^{-3}\right)\end{array}$ & $\begin{array}{c}\text { Spin } \\
\text { Density }\end{array}$ & $\begin{array}{c}\text { Wave function } \\
\text { value } \\
\left.\mathbf{1 0}^{-\mathbf{4}}\right)\end{array}$ & $\begin{array}{c}\text { Ellipticity of } \\
\text { electron } \\
\text { density }\end{array}$ \\
\hline $\mathrm{Al}(1)$ & 0.21 & 0.25 & 0.16 & 0.44 & 0.49 & 0.13 \\
\hline $\mathrm{Al}(2)$ & 0.32 & 0.12 & 0.15 & 0.24 & 0.57 & 0.23 \\
\hline $\mathrm{Mg}(1)$ & 0.35 & 0.14 & 0.20 & 0.28 & 0.46 & 0.36 \\
\hline $\mathrm{Mg}(2)$ & 0.22 & 0.16 & 0.32 & 0.32 & 0.26 & 0.44 \\
\hline $\mathrm{Ca}(1)$ & 0.24 & 0.26 & 0.38 & 0.36 & 0.28 & 0.12 \\
\hline $\mathrm{Ca}(2)$ & 0.26 & 0.28 & 0.34 & 0.44 & 0.32 & 0.34
\end{tabular}

\section{Conclusions}

In this work, theoretically, it has been discussed on the specific Calix[n] and related cation in point of density and electrical potential via electron densities \& cycle-voltammetry studies. A positive (negative) value implies that the current position is dominated by nuclear (electronic) charges. Molecular electrostatic potential (ESP) has been widely used for the prediction of nucleophilic and electrophilic sites for a long time. This result implies that the protonation of reduced Quinone is considerably inhibited when $\mathrm{Ca}^{2+}$ is bound to CDA. Generally, it is well known that the process of electron transfer to Quinone is coupled with proton transfer reaction in aqueous solution. 


\section{Funding}

The budget for this work is provided by Prof. Majid Monajjemi.

\section{Acknowledgments}

\section{Thanks to IAU, Science, and research branch for partial helps concerning providing lab and computer equipment and software.}

\section{Conflicts of Interest}

The authors declare no conflict of interest.

\section{References}

1. Gutsche, C.D.; Muthukrishnan, R.; Calixarenes. 1. Analysis of the product mixtures produced by the basecatalyzed condensation of formaldehyde with para-substituted phenols. J Org Chem 1978, 43, 4905-4906, https://doi.org/10.1021/jo00419a052.

2. Nasuhi, P.F. Calixdrugs: calixarene-based clusters of established therapeutic drug agents. Mol Divers 2016, 20, 781-787, https://doi.org/10.1007/s11030-016-9667-x

3. Perret, F.; Lazar, A.N.; Coleman, A.W. Biochemistry of the parasulfonato-calix[n]arenes. Chem Commun 2006, 42, 2425-2438, https://doi.org/10.1039/B600720C.

4. Aggarwal, B.B.; Takada, Y.; Oommen, O.V. From chemoprevention to chemotherapy: common targets and common goals. Expert Opin Investig Drugs 2006, 13, 1327-1338, https://doi.org/10.1517/13543784.13.10.1327.

5. $\quad$ Dings, R.P.M.; Chen, X.; Hellebrekers, D.M.E.I.; van, Eijk L.I.; Zhang, Y.; Hoye, T.R.; Grifoen, A.W.; Mayo, K.H. Design of nonpeptidic topomimetics of antiangiogenic proteins with antitumor activities. $J$ Natl Cancer Inst 2006, 98, 932-936, https://doi.org/10.1093/jnci/djj247.

6. Astorgues-Xerri, L.; Riveiro, M.E.; Tijeras-Raballand, A.; Serova, M.; Rabinovich GA, Bieche, I.; Vidaud, M.; de Gramont, A.; Martinet, M.; Cvitkovic, E.; Faivre, F.; Raymond, E. OTX008, a selective smallmolecule inhibitor of galectin-1, downregulates cancer cell proliferation, invasion and tumour angiogenesis. Eur J Cancer 2014, 50, 2463-2477, https://doi.org/10.1016/j.ejca.2014.06.015.

7. Dings, R.P.M.; Miller, M.C.; Nesmelova, I.; Astorgues-Xerri, L.; Kumar, N.; Serova, M.; Chen, X.; Raymond, E.; Hoye, T.R.; Mayo, K.H, Antitumor agent calixarene 0118 targets human Galectin-1 as an allosteric inhibitor of carbohydrate binding. $J$ Med Chem 2012, 55, 5121-5129, https://doi.org/10.1021/jm300014q.

8. $\quad$ Dings, R.P.M.; Vang, K.B.; Castermans, K.; Popescu, F.; Zhang, Y.; Egbrink, M.G.A.; Mescher, M.F.; Farrar, M.A.; Grifoen, A.W.; Mayo, K.H. Enhancement of T-cell-mediated antitumor response: angiostatic adjuvant to immunotherapy against cancer. Clin Cancer Res 2011, 17, 3134-3145, https://doi.org/10.1158/1078-0432.CCR-10-2443.

9. Paz, H.; Joo, E.J.; Chou, C.H.; Fei, F.; Mayo, K.H.; Abdel-Azim, H.; Ghazarian, H.; Groffen, J.; Heisterkamp, N. Treatment of B-cell precursor acute lymphoblastic leukemia with the Galectin-1 inhibitor PTX008. J Exp Clin Cancer Res 2018, 37, https://doi.org/10.1186/s13046-018-0721-7.

10. Dings, R.P.M.; Levine, J.I.; Brown, S.G.; Astorgues-Xerri, L.; MacDonald, J.R.; Hoye, T.R.; Raymond, E.; Mayo, K.H. Polycationic calixarene PTX013, a potent cytotoxic agent against tumors and drug resistant cancer. Invest New Drugs 2013, 31, 1142-1150, https://doi.org/10.1007/s10637-013-9932-0.

11. An, L.; Han, L.L.; Zheng, Y.G.; Peng, X.N.; Xue, Y.S.;Gu, X.K.; Sun, J.; Yan C.G. Synthesis, X-ray crystal structure and anti-tumor activity of calix[n]arene polyhydroxyamine derivatives. Eur J Med Chem 2016, 123, 21-30, https://doi.org/10.1016/j.ejmech.2016.07.016.

12. Richichi, B.;Comito, G.; Cerofolini, L.; Gabrielli, G.; Marra, A.; Moni, L.; Pace, A.; Pasquato, L.; Chiarugi, P.; Dondoni, A.; Toma, L.; Nativi, C. Multivalent presentation of a hydrolytically stable GM3 lactone mimetic as modulator of melanoma cells motility and adhesion. Bioorg Med Chem 2013, 21, 2756-2763, https://doi.org/10.1016/j.bmc.2013.03.021.

13. Achatz, M.I. The TP53 mutation, R337H, is associated with Li-Fraumeni and Li-Fraumeni-like syndromes in Brazilian families. Cancer Lett 2007, 245, 96-102, https://doi.org/10.1016/j.canlet.2005.12.039.

14. Gordo, S.; Martos, V.; Santos, E.; Menéndez, M.; Bo, C.; Giralt, E.; de Mendoza J. Stability and structural recovery of the tetramerization domain of $\mathrm{p} 53-\mathrm{R} 337 \mathrm{H}$ mutant induced by a designed templating ligand. Proc Natl Acad Sci USA 2008, 105, 16426-16431, https://doi.org/10.1073/pnas.0805658105.

15. Gordo, S.; Martos, V.; Vilaseca, M.; Menndez, M.; de Mendoza, J.; Giralt, E. On the role of fexibility in protein-ligand interactions: the example of p53 tetramerization domain. Chem Asian J 2011, 6, 1463-1469, https://doi.org/10.1002/asia.201000938. 
16. Blaskovich, M.A.; Lin, Q.; Delarue, F.L.; Sun, J.; Park, H.S.; Coppola, D.; Hamilton, A.D.; Sebti, S.M. Design of GFB-111, a plateletderived growth factor binding molecule with antiangiogenic and anticancer activity against human tumors in mice. Nat Biotechnol 2000, 18, 1065-1070, https://doi.org/10.1038/80257.

17. Sun, J.; Blaskovich, M.A.; Jain, R.K.; Delarue, F.; Paris, D.; Brem, S.; Wotoczek-Obadia, M.; Lin, Q.; Coppola, D.; Choi, K.; Mullan, M.; Hamilton, A.D.; Sebti, S.M. Blocking angiogenesis and tumorigenesis with GFA-116, a synthetic molecule that inhibits binding of vascular endothelial growth factor to its receptor. Cancer Res 2004, 64, 3586-3592, https://doi.org/10.1158/0008-5472.CAN-03-2673.

18. Sun, J.; Wang, D.A.; Jain, R.K.; Carie, A.; Paquette, S.; Ennis, E.; Blaskovich, MA.; Baldini, L.; Coppola, D.; Hamilton, A.D.;Sebti, S.M, Inhibiting angiogenesis and tumorigenesis by a synthetic molecule that blocks binding of both VEGF and PDGF to their receptors. Oncogene 2005, 24, 4701-4709, https://doi.org/10.1038/sj.onc.1208391.

19. Tsou, L.K.; Dutschman, G.E.; Gullen, E.A.; Telpoukhovskaia, M.; Cheng, Y.C.; Hamilton, A.D. Discovery of a synthetic dual inhibitor of HIV and HCV infection based on a tetrabutoxy-calix[4] arene scafold. Bioorg Med Chem Lett 2010, 20, 2137-2139, https://doi.org/10.1016/j.bmcl.2010.02.043.

20. Tsou, L.K.; Chen, C.H.; Dutschman, G.E.; Cheng, Y.C.; Hamilton, A.D. Blocking HIV-1 entry by a gp120 surface binding inhibitor. Bioorg Med Chem Lett 2012, 22, 3358-3361, https://doi.org/10.1016/j.bmcl.2012.02.079.

21. Marra, A.; Moni, L.; Pazzi, D.; Corallini, A.; Bridi, D.; Dondoni, A. Synthesis of sialoclusters appended to calix[4]arene platforms via multiple azide-alkyne cycloaddition. New inhibitors of hemagglutination and cytopathic efect mediated by BK and infuenza A viruses. Org Biomol Chem 2008, 6, 1396-1409, https://doi.org/10.1039/B800598B.

22. Mourer, M.; Duval, R.E.; Chantal, Finance, C.; Regnouf-de-Vains, J.B. Functional organisation and gain of activity: the case of the antibacterial tetra-para-guanidinoethyl-calix[4]arene. Bioorg Med Chem Lett 2006, 16, 2960-2963, https://doi.org/10.1016/j.bmcl.2006.02.072.

23. Mollaamin, F.; Monajjemi, M. DFT outlook of solvent effect on function of nano bioorganic drugs. Physics and Chemistry of Liquids 2012, 50, 596-604, https://doi.org/10.1080/00319104.2011.646444.

24. Mollaamin, F.; Gharibe, S.; Monajjemi, M. Synthesis of various nano and micro ZnSe morphologies by using hydrothermal method. International Journal of Physical Sciences 2011, 6, 1496-1500.

25. Monajjemi, M. Graphene/(h-BN)n/X-doped raphene as anode material in lithium ion batteries $(\mathrm{X}=\mathrm{Li}, \mathrm{Be}$, B AND N). Macedonian Journal of Chemistry and Chemical Engineering 2017, 36, 101-118, http://dx.doi.org/10.20450/mjcce.2017.1134.

26. Monajjemi, M. Cell membrane causes the lipid bilayers to behave as variable capacitors: A resonance with self-induction of helical proteins. Biophysical Chemistry 2015, 207, 114-127, https://doi.org/10.1016/j.bpc.2015.10.003.

27. Monajjemi, M. Study of CD5+ Ions and Deuterated Variants $(\mathrm{CHxD}(5-\mathrm{x})+)$ : An Artefactual Rotation. Russian Journal of Physical Chemistry A 2018, 92, 2215-2226.

28. Monajjemi, M. Liquid-phase exfoliation (LPE) of graphite towards graphene: An ab initio study. Journal of Molecular Liquids 2017, 230, 461-472, https://doi.org/10.1016/j.molliq.2017.01.044.

29. Jalilian, H.; Monajjemi, M. Capacitor simulation including of X-doped graphene (X $=\mathrm{Li}, \mathrm{Be}, \mathrm{B})$ as two electrodes and (h-BN)m (m=1-4) as the insulator. Japanese Journal of Applied Physics 2015, 54.

30. Ardalan, T.; Ardalan, P.; Monajjemi, M. Nano theoretical study of a C 16 cluster as a novel material for vitamin C carrier. Fullerenes Nanotubes and Carbon Nanostructures 2014, 22, 687-708, https://doi.org/10.1080/1536383X.2012.717561.

31. Mahdavian, L.; Monajjemi, M.; Mangkorntong, N. Sensor response to alcohol and chemical mechanism of carbon nanotube gas sensors Fullerenes Nanotubes and Carbon Nanostructures 2009, 17, 484-495, https://doi.org/10.1080/15363830903130044.

32. Monajjemi, M.; Najafpour, J. Charge density discrepancy between NBO and QTAIM in single-wall armchair carbon nanotubes. Fullerenes Nanotubes and Carbon Nano structures 2014, 22, 575-594, https://doi.org/10.1080/1536383X.2012.702161.

33. Monajjemi, M.; Hosseini, M.S. Non bonded interaction of B16 N16 nano ring with copper cations in point of crystal fields. Journal of Computational and Theoretical Nanoscience 2013, 10, 2473-2477.

34. Monajjemi, M.; Mahdavian, L.; Mollaamin, F. Characterization of nanocrystalline silicon germanium film and nanotube in adsorption gas by Monte Carlo and Langevin dynamic simulation. Bulletin of the Chemical Society of Ethiopia 2008, 22, 277-286, https://doi.org/10.4314/bcse.v22i2.61299.

35. Lee, V.S.; Nimmanpipug, P.; Mollaamin, F.; Thanasanvorakun, S.; Monajjemi, M. Investigation of single wall carbon nanotubes electrical properties and normal mode analysis: Dielectric effects. Russian Journal of Physical Chemistry A 2009, 83, 2288-2296, https://doi.org/10.1134/S0036024409130184.

36. Mollaamin, F.; Najafpour, J.; Ghadami, S.; Akrami, M.S.; Monajjemi, M. The electromagnetic feature of B $\mathrm{N} \mathrm{H}(\mathrm{x}=0,4,8,12,16$, and 20) nano rings:Quantum theory of atoms in molecules/NMR approach. Journal of Computational and Theoretical Nanoscience 2014, 11, 1290-1298.

37. Monajjemi, M.; Mahdavian, L.; Mollaamin, F.; Honarparvar, B. Thermodynamic investigation of enolketo tautomerism for alcohol sensors based on carbon nanotubes as chemical sensors. Fullerenes Nanotubes and Carbon Nanostructures 2010, 18, 45-55, https://doi.org/10.1080/15363830903291564. 
38. Monajjemi, M.; Ghiasi, R.; Seyed, S.M.A. Metal-stabilized rare tautomers: N4 metalated cytosine (M $=\mathrm{Li}$, $\mathrm{Na}, \mathrm{K}, \mathrm{Rb}$ and $\mathrm{Cs}$ ), theoretical views. Applied Organometallic Chemistry 2003, 17, 635-640, https://doi.org/10.1002/aoc.469.

39. Ilkhani, A.R.; Monajjemi, M. The pseudo Jahn-Teller effect of puckering in pentatomic unsaturated rings C $\mathrm{AE}, \mathrm{A}=\mathrm{N}, \mathrm{P}, \mathrm{As}, \mathrm{E}=\mathrm{H}, \mathrm{F}, \mathrm{Cl}$.Computational and Theoretical Chemistry 2015, 1074, 19-25, http://dx.doi.org/10.1016\%2Fj.comptc.2015.10.006.

40. Monajjemi, $\mathrm{M}$. Non-covalent attraction of $\mathrm{B} \mathrm{N}$ and repulsion of $\mathrm{B} \mathrm{N}$ in the $\mathrm{B} \mathrm{N}$ ring: a quantum rotatory due to an external field. Theoretical Chemistry Accounts 2015, 134, 1-22, https://doi.org/10.1007/s00214-0151668-9.

41. Monajjemi, M.; Naderi, F.; Mollaamin, F.; Khaleghian, M. Drug design outlook by calculation of second virial coefficient as a nano study. Journal of the Mexican Chemical Society 2012, 56, 207-211, https://doi.org/10.29356/jmcs.v56i2.323.

42. Monajjemi, M.; Bagheri, S.; Moosavi, M.S. Symmetry breaking of B2N(-,0,+): An aspect of the electric potential and atomic charges. Molecules 2015, 20, 21636-21657, https://doi.org/10.3390/molecules201219769.

43. Monajjemi, M.; Mohammadian, N.T. S-NICS: An aromaticity criterion for nano molecules. Journal of Computational and Theoretical Nanoscience 2015, 12, 4895-4914, https://doi.org/10.1166/jctn.2015.4458.

44. Monajjemi, M.; Ketabi, S.; Hashemian, Z.M.; Amiri, A. Simulation of DNA bases in water: Comparison of the Monte Carlo algorithm with molecular mechanics force fields. Biochemistry (Moscow) 2006, 71, 1-8, https://doi.org/10.1134/s0006297906130013.

45. Monajjemi, M.; Lee, V.S.; Khaleghian, M.; Honarparvar, B.; Mollaamin, F. Theoretical Description of Electromagnetic Nonbonded Interactions of Radical, Cationic, and Anionic NH2BHNBHNH2 Inside of the B18N18 Nanoring. J. Phys. Chem C 2010, 114, 15315-15330, https://doi.org/10.1021/jp104274z.

46. Monajjemi, M.; Boggs, J.E. A New Generation of BnNn Rings as a Supplement to Boron Nitride Tubes and Cages. J. Phys. Chem. A 2013, 117, 1670-1684, http://dx.doi.org/10.1021/jp312073q.

47. Monajjemi, M. Non bonded interaction between BnNn (stator) and BN B (rotor) systems: A quantum rotation in IR region. Chemical Physics 2013, 425, 29-45, https://doi.org/10.1016/j.chemphys.2013.07.014.

48. Monajjemi, M.; Robert, W.J.; Boggs, J.E. NMR contour maps as a new parameter of carboxyl's OH groups in amino acids recognition: A reason of tRNA-amino acid conjugation. Chemical Physics 2014, 433, 1-11, https://doi.org/10.1016/j.chemphys.2014.01.017.

49. Monajjemi, M. Quantum investigation of non-bonded interaction between the B15N15 ring and BH2NBH2 (radical, cation, and anion) systems: a nano molecularmotor. Struct Chem 2012, 23, 551-580, http://dx.doi.org/10.1007/s11224-011-9895-8.

50. Monajjemi, M. Metal-doped graphene layers composed with boron nitride-graphene as an insulator: a nanocapacitor. Journal of Molecular Modeling 2014, 20, https://doi.org/10.1007/s00894-014-2507-y.

51. Mollaamin, F.; Monajjemi, M.; Mehrzad, J. Molecular Modeling Investigation of an Anti-cancer Agent Joint to SWCNT Using Theoretical Methods. Fullerenes nanotubes and carbon nanostructures 2014, 22, 738751, https://doi.org/10.1080/1536383X.2012.731582.

52. Monajjemi, M.; Ketabi, S.; Amiri, A. Monte Carlo simulation study of melittin: protein folding and temperature ependence, Russian journal of physical chemistry 2006, 80, S55-S62, https://doi.org/10.1134/S0036024406130103.

53. Monajjemi, M; Heshmata, M; Haeria, H.H. QM/MM model study on properties and structure of some antibiotics in gas phase: Comparison of energy and NMR chemical shift. Biochemistry-moscow 2006, 71, S113-S122, https://doi.org/10.1134/S0006297906130190.

54. Monajjemi, M.; Afsharnezhad, S.; Jaafari, M.R.; Abdolahi, A.N.; Monajemi, H. NMR shielding and a thermodynamic study of the effect of environmental exposure to petrochemical solvent on DPPC, an important component of lung surfactant. Russian journal of physical chemistry A 2007, 81, 1956-1963, https://doi.org/10.1134/S0036024407120096.

55. Mollaamin, F.; Noei, M.; Monajjemi, M.; Rasoolzadeh, R. Nano theoretical studies of fMet-tRNA structure in protein synthesis of prokaryotes and its comparison with the structure of fAla-tRNA. African journal of microbiology research 2011, 5, 2667-2674, https://doi.org/10.5897/AJMR11.310.

56. Monajjemi, M.; Heshmat, M.; Haeri, H.H.; Kaveh, F. Theoretical study of vitamin properties from combined QM-MM methods: Comparison of chemical shifts and energy. Russian journal of physical chemistry 2006, 80, 1061-1068, https://doi.org/10.1134/S0036024406070119.

57. Monajjemi, M; Chahkandi, B. Theoretical investigation of hydrogen bonding in Watson-Crick, Hoogestein and their reversed and other models: comparison and analysis for configurations of adenine-thymine base pairs in 9 models. Journal of molecular structure-theochem 2005, 714, 43-60, https://doi.org/10.1016/j.theochem.2004.09.048.

58. Monajjemi, M.; Honarparvar, B.; Haeri, H.H.; Heshmat, M. An ab initio quantum chemical investigation of solvent-induced effect on N-14-NQR parameters of alanine, glycine, valine, and serine using a polarizable continuum model. Russian journal of physical chemistry 2006, 80, S40-S44, https://doi.org/10.1134/S0036024406130073. 
59. Monajjemi, M.; Seyed Hosseini, M. Non Bonded Interaction of $\mathrm{B}_{16} \mathrm{~N}_{16}$ Nano Ring with Copper Cations in Point of Crystal Fields. Journal of Computational and Theoretical Nanoscience 2013, 10, 2473-2477, https://doi.org/10.1166/jctn.2013.3233.

60. Monajjemi, M.; Farahani, N.; Mollaamin, F. Thermodynamic study of solvent effects on nanostructures: phosphatidylserine and phosphatidylinositol membranes. Physics and chemistry of liquids 2012, 50, 161172, https://doi.org/10.1080/00319104.2010.527842.

61. Monajjemi, M.; Ahmadianarog, M. Carbon Nanotube as a Deliver for Sulforaphane in Broccoli Vegetable in Point of Nuclear Magnetic Resonance and Natural Bond Orbital Specifications. Journal of computational and theoretical nanoscience 2014, 11, 1465-1471, https://doi.org/10.1166/jctn.2014.3519.

62. Monajjemi, M.; Ghiasi, R.; Ketabi, S.; Passdar, H.; Mollaamin, F. A Theoretical Study of Metal-Stabilised Rare Tautomers Stability: N4 Metalated Cytosine $\left(\mathrm{M}=\mathrm{Be}^{2+}, \mathrm{Mg}^{2+}, \mathrm{Ca}^{2+}, \mathrm{Sr}^{2+}\right.$ and $\left.\mathrm{Ba}^{2+}\right)$ in $\mathrm{Gas}$ Phase and Different Solvents. Journal of Chemical Research 2004, 1, 11-18, https://doi.org/10.3184/030823404323000648.

63. Monajjemi, M.; Baei, M.T.; Mollaamin, F. Quantum mechanic study of hydrogen chemisorptions on nanocluster vanadium surface. Russian journal of inorganic chemistry 2008, 53, 1430-1437, https://doi.org/10.1134/S0036023608090143.

64. Mollaamin, F.; Baei, M.T.; Monajjemi, M.; Zhiani, R.; Honarparvar, B. A DFT study of hydrogen chemisorption on V (100) surfaces. Russian journal of physical chemistry A 2008, 82, 2354-2361, https://doi.org/10.1134/S0036024408130323.

65. Monajjemi, M.; Honarparvar, B.; Nasseri, S.M.; Khaleghian, M. NQR and NMR study of hydrogen bonding interactions in anhydrous and monohydrated guanine cluster model: A computational study. Journal of structural chemistry 2009, 50, 67-77, https://doi.org/10.1007/s10947-009-0009-z.

66. Monajjemi, M.; Aghaie, H.; Naderi, F. Thermodynamic study of interaction of TSPP, CoTsPc, and FeTsPc with calf thymus DNA. Biochemistry-Moscow 2007, 72, 652-657, https://doi.org/10.1134/S0006297907060089.

67. Monajjemi, M.; Heshmat, M.; Aghaei, H.; Ahmadi, R.; Zare, K. Solvent effect on N-14 NMR shielding of glycine, serine, leucine, and threonine: Comparison between chemical shifts and energy versus dielectric constant. Bulletin of the chemical society of ethiopia 2007, 21, 111-116, https://doi.org/10.4314/bcse.v21i1.61387.

68. Monajjemi, M.; Rajaeian, E.; Mollaamin, F.; Naderi, F.; Saki, S. Investigation of NMR shielding tensors in 1,3 dipolar cycloadditions: solvents dielectric effect. Physics and chemistry of liquids 2008, 46, 299-306, https://doi.org/10.1080/00319100601124369.

69. Mollaamin, F.; Varmaghani, Z.; Monajjemi, M. Dielectric effect on thermodynamic properties in vinblastine by DFT/Onsager modelling. Physics and chemistry of liquids 2011, 49, 318-336, https://doi.org/10.1080/00319100903456121.

70. Monajjemi, M.; Honaparvar, B.; Hadad, B.K.; Ilkhani, A.R.; Mollaamin, F. Thermo-chemical investigation and NBO analysis of some anxileotic as Nano-drugs. African journal of pharmacy and pharmacology 2010, 4, 521-529.

71. Monajjemi, M.; Khaleghian, M.; Mollaamin, F. Theoretical study of the intermolecular potential energy and second virial coefficient in the mixtures of $\mathrm{CH} 4$ and $\mathrm{Kr}$ gases: a comparison with experimental data. Molecular simulation 2010, 11, 865-870, https://doi.org/10.1080/08927022.2010.489557.

72. Monajjemi, M.; Khosravi, M.; Honarparvar, B.; Mollamin, F. Substituent and Solvent Effects on the Structural Bioactivity and Anticancer Characteristic of Catechin as a Bioactive Constituent of Green Tea. International journal of quantum chemistry 2011, 111, 2771-2777, https://doi.org/10.1002/qua.22612.

73. Tahan, A.; Monajjemi, M. Solvent Dielectric Effect and Side Chain Mutation on the Structural Stability of Burkholderia cepacia Lipase Active Site: A Quantum Mechanical/ Molecular Mechanics Study. Biotheoretica 2011, 59, 291-312, https://doi.org/10.1007/s10441-011-9137-x.

74. Monajjemi, M.; Khaleghian, M. EPR Study of Electronic Structure of [CoF6](3-)and B18N18 Nano Ring Field Effects on Octahedral Complex. Journal of cluster science 2011, 22, 673-692, https://doi.org/10.1007/s10876-011-0414-2.

75. Monajjemi, M; Mollaamin, F. Molecular Modeling Study of Drug-DNA Combined to Single Walled Carbon Nanotube, Journal of cluster science 2012, 23, 259-272, https://doi.org/10.1007/s10876-011-0426-y.

76. Mollaamin, F; Monajjemi, M. Fractal Dimension on Carbon Nanotube-Polymer Composite Materials Using Percolation Theory. Journal of computational and theoretical nanoscience 2012, 9, 597-601, https://doi.org/10.1166/jctn.2012.2067.

77. Mahdavian, L.; Monajjemi, M. Alcohol sensors based on SWNT as chemical sensors: Monte Carlo and Langevin dynamics simulation. Microelectronics journal 2010, 41, 142-149, https://doi.org/10.1016/j.mejo.2010.01.011.

78. Monajjemi, M.; Falahati, M.; Mollaamin, F. Computational investigation on alcohol nanosensors in combination with carbon nanotube: a Monte Carlo and ab initio simulation. Ionics 2013, 19, 155-164, https://doi.org/10.1007/s11581-012-0708-x.

79. Lu, T.; Chen, F. Multiwfn: A Multifunctional Wave-function Analyzer. J. Comp. Chem. 2012, 33, 580-592, https://doi.org/10.1002/jcc.22885. 